\title{
Adenoid cystic carcinoma of the cervix uteri
}

INSERM

\section{Source}

INSERM. (1999). Orphanet: an online rare disease and orphan drug data base. Adenoid cystic carcinoma of the cervix uteri. ORPHA:213823

Adenoid cystic carcinoma of the cervix uteri is a rare, highly aggressive uterine cancer, macroscopically appearing as an irregular, slow-growing, non-friable, polypoid mass on the uterine cervix and histologically showing a pseudog landular or cribriform growth pattern. It presents with vag inal bleeding and discharge and abdominal or pelvic pain. The tumor is highly infiltrative, often associated with vascular, lymphatic and perineural invasion, with subsequent haematogenous spread and early recurrence. 